\title{
IL-13 signaling in liver fibrogenesis
}

\author{
Yan Liu ${ }^{1}$, Stefan Munker ${ }^{1}$, Roman Müllenbach ${ }^{1,2}$ and Hong-Lei Weng ${ }^{1}{ }^{*}$ \\ ${ }^{1}$ Molecular Hepatology - Alcohol Associated Diseases, II. Medical Clinic Faculty of Medicine at Mannheim, University of Heidelberg, Mannheim, Germany \\ 2 Department of Medicine II, Saarland University Hospital, Homburg, Germany
}

\section{Edited by:}

Jose Fernando Bazan, NeuroScience, Inc., USA

\section{Reviewed by:}

António Castro, University of Minho, Portugal

Koji Yasutomo, University of

Tokushima, Japan

*Correspondence:

Hong-Lei Weng, Molecular

Hepatology - Alcohol Associated

Diseases, II. Medical Clinic Faculty of

Medicine Mannheim, University of

Heidelberg, Theodor-Kutzer Ufer 1-3,

68167 Mannheim, Germany.

e-mail: honglei.weng@medma.

uni-heidelberg.de
Liver fibrosis is the final common pathway of chronic liver diseases irrespective of etiology. However, etiology deeply impacts progression and characteristics of liver fibrogenesis. IL13 is the dominant pro-fibrotic cytokine in Schistosomiasis associated liver fibrogenesis. In vitro, IL-13 directly induces expression of fibrosis-associated genes, e.g., collagens or connective tissue growth factor, in hepatic stellate cells. Recently, potential effects of IL-13 in non-Schistosomiasis associated liver fibrosis have been uncovered. This review summarizes the potential roles of IL-13 in chronic liver disease of different etiologies, and the downstream events mediating IL-13 signaling in liver fibrogenesis.

\section{Keywords: schistosomiasis, Th2 cell, STAT6, hepatic stellate cell}

\section{INTRODUCTION}

Fibrosis is a leading cause of morbidity and mortality worldwide. In the USA, $45 \%$ of all deaths can be attributed to fibrotic disorders (Wynn, 2004). In the liver, fibrosis and its end stage, cirrhosis, is the final common pathway of chronic liver diseases irrespective of etiology (Iredale, 2007). Liver cirrhosis represents not only increased scarring and fibrosis, but also distortion of the liver architecture in association with nodule formation and altered blood flow (Friedman, 2008). Patients with liver cirrhosis are facing tremendous risks of hepatic failure and hepatocellular carcinoma (Friedman, 2008). So far, there is no gold-standard treatment for liver fibrosis and cirrhosis.

Advancement of liver fibrosis is a dynamic process characterized by accumulation exceeding degradation of extracellular matrix (ECM). Over the last two decades, sinusoidal resident hepatic stellate cells (HSC) have been commonly recognized as the major source of ECM. In most chronic liver diseases, HSC activation and transdifferentiation into myofibroblasts (MFBs) are key events in liver fibrogenesis (Friedman, 2008). The initiation phase of HSC activation is due to paracrine stimuli from injured neighboring cells, including hepatocytes, Kupffer cells, sinusoidal endothelial cells, platelets, and infiltrating inflammatory cells. These damaged cells secret a number of cytokines to

\footnotetext{
Abbreviations: ASH, alcoholic steatohepatitis; CTGF, connective tissue growth factor; dSSc, diffuse cutaneous SSc; ECM, extracellular matrix; HSC, hepatic stellate cells; IIP, idiopathic interstitial pneumonia; IL, Interleukin; iNKT, invariant Natural killer T; KO, knockout; MFB, myofibroblast; 1SSc, limited cutaneous SSc; NASH, non-alcoholic steatohepatitis; NSIP, non-specific interstitial pneumonia; RA, rheumatoid arthritis; S. japonicum, Schistosoma japonicum; S. mansoni, Schistosoma mansoni; $\alpha$-SMA, alpha-smooth muscle actin; SCID, severe combined immunodeficiency; sIL-13R $\alpha 2$-Fc, soluble IL-13 receptor alpha2-Fc-fusion protein; SSc, systemic sclerosis; Stat6, signal transducer and activator of transcription; TGF, transforming growth factor
}

activate HSC. One important cytokine among them is transforming growth factor (TGF)- $\beta$. Activated HSC perpetuate their own activation by several autocrine loops, including the secretion of TGF- $\beta$ and upregulation of its receptors. Furthermore, overexpression of TGF- $\beta$ promotes HSC survival in damaged liver (Bataller and Brenner, 2005; Mann and Marra, 2010).

As the most important pro-fibrotic mediator in liver fibrosis (Gressner et al., 2002; Friedman, 2008), the role of TGF- $\beta$ has been intensively studied in a large amount of in vitro and animal models. However, in patients with chronic liver diseases, the effects of TGF- $\beta$ in liver fibrogenesis are etiology dependent (Weng et al., 2009). For example, TGF- $\beta$ and its downstream signaling protein, phospho-Smad2, display high positive correlation with fibrosis degree in patients with chronic HBV infection, alcoholic steatohepatitis (ASH), and non-alcoholic steatohepatitis (NASH), but not in those with chronic HCV infection. In patients infected with Schistosoma mansoni or S. japonicum, TGF- $\beta$ demonstrates negative correlation with fibrosis stages (Weng et al., 2009; Table 1).

Besides TGF- $\beta$, Interleukin (IL)-13 is recognized as another critical pro-fibrotic cytokine in various organs, including liver. It has been identified as the dominant effector cytokine of Schistosomiasis associated liver fibrogenesis (Wynn, 2003, 2004, 2008). Over the last decade, the potential roles of IL-13 in non-Schistosomiasis associated liver fibrogenesis were reported (Weng et al., 2009; Jin et al., 2011). In this review, we aim to provide up-to-date information on the role of IL-13 and its downstream signaling in fibrogenesis, especially in the liver.

\section{IL-13 IN LIVER FIBROSIS SCHISTOSOMIASIS}

IL-13 directly induces expression of collagen I and other critical fibrosis-associated genes, e.g., $\alpha$-smooth muscle actin (SMA) and 
Table 1 | Correlation between TGF- $\beta / p-S m a d 2$ and IL-13 in liver fibrosis patients with different etiologies.

\begin{tabular}{|c|c|c|}
\hline & TGF- $\beta / p-S m a d 2$ & IL-13 \\
\hline HBV & $\begin{array}{l}\text { High positive correlation (Stickel et al., 2001; Akpolat et al., 2005; } \\
\text { Weng et al., 2009) }\end{array}$ & Positive correlation Weng et al., 2009) \\
\hline $\mathrm{HCV}$ & No correlation (Roulot et al., 1995; Weng et al., 2009) & Positive correlation Weng et al., 2009) \\
\hline $\mathrm{ASH}$ & High positive correlation (Weng et al., 2009) & High positive correlation (Weng et al., 2009) \\
\hline NASH & High positive correlation (Weng et al., 2009) & $\begin{array}{l}\text { High positive correlation (Shimamura et al., 2008; Weng et al., } \\
\text { 2009) }\end{array}$ \\
\hline Schistosomiasis & Negative correlation (Alves Oliveira et al., 2006; Weng et al., 2009) & High positive correlation (Booth et al., 2004; Weng et al., 2009) \\
\hline Others & Unknown & Unknown \\
\hline
\end{tabular}

connective tissue growth factor (CTGF), in HSC, the major ECM producing source during liver fibrogenesis (Sugimoto et al., 2005; Weng et al., 2009; Liu et al., 2011). So far, most studies involving the role of IL-13 in liver fibrogenesis are implicated in Schistosomiasis. S. mansoni or S. japonicum infection causes serious pathogenic changes in human organs, including lung, intestine, and especially liver (Wynn et al., 2004b). The worms inside human mesenteric veins lay numerous eggs that are finally carried to the liver and deposited in portal veins. The eggs induce granulomas and lead to liver fibrosis (Wynn et al., 2004b). From acute to chronic infection of Schistosoma, patients with Schistosomiasis undergo T-cell polarization from Th1 cell to Th2 cell dominant (Wynn, 2003). Due to its predominant role in Th2 development, IL-4 is hypothesized as a potential crucial cytokine regulating schistosoma associated liver fibrosis. Interfering with IL-4 influences liver fibrogenesis in S. mansoni infected mouse models has been reported in early studies (Cheever et al., 1994, 1999). Cheever and colleagues showed that neutralizing IL-4 by antibody markedly decreases hepatic collagen deposition. In addition, anti-IL-4 treatment decreases mRNA expression of Th2 cytokines, e.g., IL-5 and IL-13, and increases mRNA expression of Th1 cytokines, e.g., IFN- $\gamma$ and IL-2, in the liver infected with $S$. mansoni (Cheever et al., 1994). Later, the same group found that severe combined immunodeficiency (SCID) mice formed smaller hepatic granulomas and less fibrosis compared to wild-type mice. The reduction in egg-associated pathology in SCID mice correlates with marked decreases in mRNA expression of IL-4, IL-5, IL-13, and IFN- $\gamma$ in the liver (Cheever et al., 1999). However, IL-4 knockout (KO) mice infected with $S$. mansoni do not significantly reduce granuloma volume (Cheever et al., 1994; Metwali et al., 1996; Pearce et al., 1996). Jankovic et al. compared schistosoma associated pathology between IL-4 $\mathrm{KO}$ and IL-4 receptor $\mathrm{KO}$ mice. In contrast to IL-4 $\mathrm{KO}$ mice, IL-4 receptor $\mathrm{KO}$ mice developed only minimal hepatic granulomas and fibrosis despite the equivalent lymphocytic profile in both models (Jankovic et al., 1999). These results suggest that IL-4 receptor associated factors, but not IL-4, are critical for regulating granuloma formation.

Subsequently three hallmark studies compared the role of IL-4 and IL-13 in granuloma formation and liver fibrosis of S. mansoni infected mice (Chiaramonte et al., 1999a,b; Fallon et al., 2000). Chiaramonte et al. (1999b) confirmed that IL-13 is the key cytokine to regulate granuloma formation in S. mansoni infected mice. They showed that IL-4 KO mice do not decrease collagen I and III expression after S. mansoni infection (Chiaramonte et al., 1999b; Fallon et al., 2000). In contrast to IL-4, a soluble IL-13 receptor $\alpha 2$-Fc-fusion protein (sIL-13R $\alpha 2-F c$ ), which successfully neutralizes IL-13 in vitro and in vivo (Donaldson et al., 1998; Chiaramonte et al., 1999b), markedly inhibits expression of collagen I and III (Chiaramonte et al., 1999a). Using IL-4 KO, IL-13 KO and IL-4/IL-13 double KO mice, Fallon et al. found that both IL-4 and IL-13 are required for granuloma formation in mice infected with S. mansoni. IL-4 or IL-13 single knockout does not influence granuloma volume in the liver after S. mansoni infection. However, IL-4/IL-13 double KO mice demonstrated significantly reduced granuloma in the liver as compared to wild-type or IL4/IL-13 single knockout mice. IL-13 KO and IL-4/IL-13 double KO mice markedly improved liver fibrosis whereas IL-4 KO does not change collagen deposition and liver fibrosis after S. mansoni infection (Fallon et al., 2000). These results clearly suggest that IL-4 and IL-13 have distinct roles in S. mansoni infected mice and that IL-13, but not IL-4 is the dominant pro-fibrotic mediator in this disease.

Chiaramonte et al. (2001) further investigated the role of IL-13 on different genetic backgrounds of mice infected with S. mansoni. They found that $\mathrm{C} 3 \mathrm{H} / \mathrm{HeN}, \mathrm{BALB} / \mathrm{c}$, and $\mathrm{C} 57 \mathrm{BL} / 6$ mice develop high, intermediate, and low levels of fibrosis, respectively. The fibrotic mechanism of $S$. mansoni infection tightly correlates with high IL-13 and low IFN- $\gamma /$ IL-10. Administration of sIL-13R $\alpha 2-F c$ markedly improves liver fibrosis in all strains. More interestingly, sIL-13R $\alpha 2-F c$ is highly efficient even when S. mansoni mediated fibrosis and Th2 cytokine response have been developed (Chiaramonte et al., 2001). As a decoy receptor, IL-13R $\alpha 2$ is upregulated by P-selectin in S. mansoni infection (Wynn et al., 2004a). IL-13R $\alpha 2-$ deficient mice showed a marked exacerbation in S. mansoni associated liver fibrosis due to increased IL-13 activity (Chiaramonte et al., 2003; Mentink-Kane et al., 2004).

The pro-fibrotic effects of IL-13 are dependent of TGF- $\beta$ in lung fibrosis (Lee et al., 2001; Fichtner-Feigl et al., 2006). However, IL13 mediated liver fibrosis in schistosomiasis is TGF- $\beta$ and MMP-9 independent (Kaviratne et al., 2004). S. mansoni infected IL-13 KO mice almost completely abrogates liver fibrosis in spite of undiminished TGF- $\beta$ production. Further, interfering with TGF- $\beta$ and its signaling by neutralizing anti-TGF- $\beta$ antibody, soluble TGF$\beta \mathrm{R}-\mathrm{Fc}$ and establishing Smad3 KO and TGF- $\beta$ RII-Fc transgenic mice does not modulate development of liver fibrosis and production of IL-13 in S. mansoni infected mice. Like TGF- $\beta$, MMP-9 
knockout shows no reduction of liver fibrosis in S. mansoni mouse model either (Kaviratne et al., 2004). These results suggest direct pro-fibrotic mechanisms of IL-13 in schistosoma infected mice.

Consistent with the findings from animal models, the tight link between IL-13 and liver fibrosis was demonstrated in patients with Schistosomiasis. One study demonstrated significantly higher levels of PBMC IL-13, IL-5, and IL-10 in S. mansoni infected patients with degree III hepatic fibrosis than in those with degree I and II hepatic fibrosis (de Jesus et al., 2004). Another study performed in 91 patients with $S$. mansoni infection confirmed a positive correlation between levels of IL-13 and liver fibrosis (Alves Oliveira et al., 2006). Interestingly, this study showed that high levels of TGF- $\beta$ negatively associated with liver fibrosis in S. mansoni infected patients (Alves Oliveira et al., 2006). A similar result demonstrated that TGF- $\beta$ downstream signaling protein, phospho-Smad2, negatively correlates with fibrotic stages in liver tissues from patients with $S$. japonicum infection (Weng et al., 2009). Moreover, a study on 611 patients with S. japonicum infection in the Philippines further confirmed the association of Th2 cytokines, including IL-4, IL-5, and IL-13, with liver fibrosis (Coutinho et al., 2007).

\section{HCV}

Although Th1 to Th2 shift has been thought as a critical determination in chronic hepatitis $\mathrm{C}$, this disease is not a typical Th2 dominated chronic disease. A clinical study failed to find significantly different levels of IL-4 and IL-13 in peripheral serum CD4+, CD8+, "naïve"-CD45RA 1, and "memory"-CD45RO 1 Tcell subsets from 28 patients with chronic HCV infection versus 26 matched controls (Bergamini et al., 2001). However, patients with chronic HCV infection show Th2 biased characteristics in Natural killer T (NKT) cells. Invariant NKT (iNKT) cells secrete both Th1 and Th2 cytokines in chronic HCV infection. Although the frequency of serum NKT cells in patients with chronic HCV infection does not differ from those in healthy controls, activated NKT cells produce higher levels of IL-13 but comparable levels of IFN- $\gamma$ with those from healthy subjects (Kanto and Hayashi, 2007). Another study focusing on human iNKT cells reported that levels of IL-13 and IL-4 in iNKT cells are markedly increased in either peripheral or intrahepatic tissues in patients with chronic HBV or HCV infection compared to healthy controls (de Lalla et al., 2004). Further, levels of IL-13 and IL-4 in patients with cirrhosis were significantly higher than in those without cirrhosis (de Lalla et al., 2004). When Durante-Mangoni and colleagues investigated hepatic CD1d expression in HCV infection, they found that intrahepatic lymphocytes recognizing CD1d produce high levels of IFN- $\gamma$ and some IL-13, but little or no detectable IL-4. However, cirrhotic liver CD1d reactive T cells could also produce IL-4 (Durante-Mangoni et al., 2004). Another study reported no difference in numbers of iNKT cells in pheripheral serum of patients with chronic HCV infection, but iNKT cells from HCV patients demonstrate significantly enhanced capability to secret IL-13 compared to those from healthy controls (Inoue et al., 2006). Furthermore, a recent study revealed significantly enhanced serum levels of IL-13 in HCV patients compared to healthy controls (Weng et al., 2009). Markedly elevated protein expression of IL-13 is detected in patients with HCV associated cirrhosis. In addition,
IL-13 immunohistochemical score correlated with liver fibrotic stages in these patients (Weng et al., 2009).

\section{HBV}

Compared to HCV and NASH/ASH, IL-13 levels in liver tissues with chronic HBV infection are much lower (Weng et al., 2009). However, there is still evidence that IL-13 is functionally related to HBV associated liver fibrosis. A recent study with HBV transgenic mice reported that either IL-13 or IL-4 derived from NKT cells is critical for HSC activation (Jin et al., 2011). In this study, Jin and colleagues investigated liver fibrosis in an HBV transgenic mouse model. They found that NKT cells are critical in mediating HBV associated liver fibrogenesis. Enhanced IL-13 and IL-4 expression were detected in NKT cells in HBV transgenic animals compared to wild-type mice. Neutralizing monoclonal antibodies against IL13 and IL- 4 markedly inhibited the expression of $\alpha$-SMA in HSC isolating from $\mathrm{HBV}$ transgenic mice, suggesting that both IL-13 and IL-4 participate in HSC activation.

\section{NASH AND ASH}

IL-13 serum levels are increased in patients with NASH compared to healthy controls (Shimamura et al., 2008). In addition, upregulated expression of IL-13 in liver tissues from patients with NASH and ASH was also reported (Weng et al., 2009). Moreover, Shimamura et al. (2008) detected significantly increased IL-13R $\alpha 2$ expression in activated HSC in biopsied liver tissues from patients with NASH, but not in healthy controls and patients with NAFLD, suggesting that instead of function as a decoy receptor, IL-13R $\alpha 2$ may be required for IL-13 mediated liver fibrosis in NASH (Shimamura et al., 2008).

\section{IL-13 IN EXTRAHEPATIC FIBROSIS}

Besides Schistosomiasis, Th2 type cytokines are dominant in a series of fibrotic diseases, including interstitial lung disease, systemic sclerosis, rheumatoid arthritis (RA), and Ulcerative colitis (UC; Wynn, 2003, 2004, 2008).

In idiopathic interstitial pneumonia (IIP), IL-13 expression in tissue and in bronchoalveolar lavage (BAL) fluid is elevated in the most common subgroup, idiopathic pulmonary fibrosis (IPF). IPF is considered a Th2 type disease with inflammatory infiltrates prevalent. IL-13 levels were higher in IPF than in the non-specific interstitial pneumonia (NSIP), the second most common IIP without inflammatory infiltrates, but with less fibrosis and better prognosis (Park et al., 2009). In progressed stages of sarcoidosis, IL-13 expression is highly elevated in BAL and in peripheral blood mononuclear cells, compared to lower disease grades and healthy controls (Hauber et al., 2003), suggesting the elevated expression of IL-13 might be a potential therapeutic avenue in this disease. The connection of IL-13 to lung fibrosis was further strengthened in animal models. In a mouse model of chronic asthma, IL-13 proved paramount in airway remodeling, eosinophile accumulation and fibrosis (Kumar et al., 2002). Further, inhibition of IL-13 signaling via blocking antibodies underlined the importance of IL-13 in interstitial lung disease, either in animals which were challenged with Aspergillus fumigatus Conidiae (Blease et al., 2001), or animals with bleomycin-induced lung fibrosis (Belperio et al., 2002). In transgenic mice, overexpressing IL-13 in the lungs resulted in fibrosis (Zhu et al., 1999). 
Further studies showed that IL-13 stimulates airway remodeling via induction of specific MMP's (Lanone et al., 2002), and IL-13 is capable of acting directly on airway fibroblasts and supporting their proliferation (Belperio et al., 2002) via induction of PDGF-alpha (Ingram et al., 2004).

Elevated IL-13 levels have also been reported in systemic sclerosis, in RA, and other rheumatic diseases (Spadaro et al., 2002). The first study connecting IL-13 to systemic sclerosis (SSc) was published in 1997. The authors showed significantly elevated IL13 levels in the sera of patients with limited cutaneous SSc (ISSc) and diffuse cutaneous SSc (dSSc) compared to healthy individuals (Hasegawa et al., 1997). Further, IL-13 levels were found to correlate to more aggressive stages of disease (Riccieri et al., 2003). In an animal model of systemic sclerosis, in which Bleomycin is administered subcutaneously, similar observations have been achieved (Matsushita et al., 2004). Consequently, Wynn et al. proved that IL-13 is responsible for the fibrosis in bleomycin-induced SSc, and its expression is regulated by the transcription factor T-bet (Aliprantis et al., 2007).

Rheumatoid arthritis, a disease in which joint inflammation and fibrosis occurs, has long been regarded as a Th1 cell induced disease and lack of Th2 responses (Toh and Miossec, 2007). Recent studies demonstrate that Th17 cells play important roles in RA (Toh and Miossec, 2007). However, besides Th1 and Th17 cells secreted cytokines, increased IL-13 levels in patients' sera and synovial fluids were also detected (Isomaki et al., 1996; Spadaro et al., 2002). Further, Treatment with anti-TNF alpha antibody decreases IL-13 levels (Spadaro et al., 2002; Tokayer et al., 2002). Another study also showed elevated IL-13 levels in Still's disease, an adult form of juvenile RA (Saiki et al., 2004). However, animal models which connect Il-13 to extensive scarring in RA are still missing to date.
Ulcerative colitis is also considered a TH2 type disease, with recurring episodes of colonic inflammation, and in the terminal stadium widespread fibrosis occurs. It is hypothesized that IL13 derived from mononuclear cells, is involved in the pathogenic changes (Heller et al., 2005). However, in an animal model of colitis, IL-13 proved to be beneficial in preventing inflammatory changes (Wilson et al., 2011), whereas another study points out its proinflammatory role in UC (Kawashima et al., 2011).

\section{IL-13 RECEPTORS AND IL-13 SIGNALING IN FIBROSIS}

IL-13 signals to cells by binding to a complex receptor system comprised of IL-4R $\alpha$ and two IL-13 binding proteins, IL-13R $\alpha 1$ and IL-13R $\alpha 2$ (Zhang et al., 1997). IL-13 R $\alpha 1$ is expressed in healthy tissue and binds IL-13 with low affinity by itself, but when paired with IL- $4 \alpha$, it binds IL-13 with high affinity and forms a functional IL-13 receptor that signals and results in activation of JAK/Stat6 pathway (Hershey, 2003; Figure 1). IL-13R $\alpha 2$, on the other hand, is only marginally expressed in normal tissues, but over-expressed in several abnormal conditions, including in cancer cells and during fibrosis (Jakubzick et al., 2002, 2004; Joshi et al., 2006). In contrast to its interaction with the IL-13R $\alpha 1$, IL13 shows higher affinity binding to IL-13R $\alpha 2$ which has a short cytoplasmic tail and thus is generally considered a decoy receptor in murine system as described above (Chiaramonte et al., 2003; Mentink-Kane et al., 2004; Wynn et al., 2004a). However, Fichtner-Feigl et al. recently reported that IL-13 signals through IL-13R $\alpha 2$ to induce production of TGF- $\beta 1$ in murine macrophage cell line. Silencing IL-13R $\alpha 2$ markedly reduces TGF- $\beta 1$ and ameliorates bleomycin-induced mouse lung fibrosis (Fichtner-Feigl et al., 2006). Furthermore, IL-13 signals through IL-13R $\alpha 2$ in HSC leading to TGF- $\beta 1$ production and liver fibrosis in vitro and in a NASH model (Shimamura et al., 2008). These findings

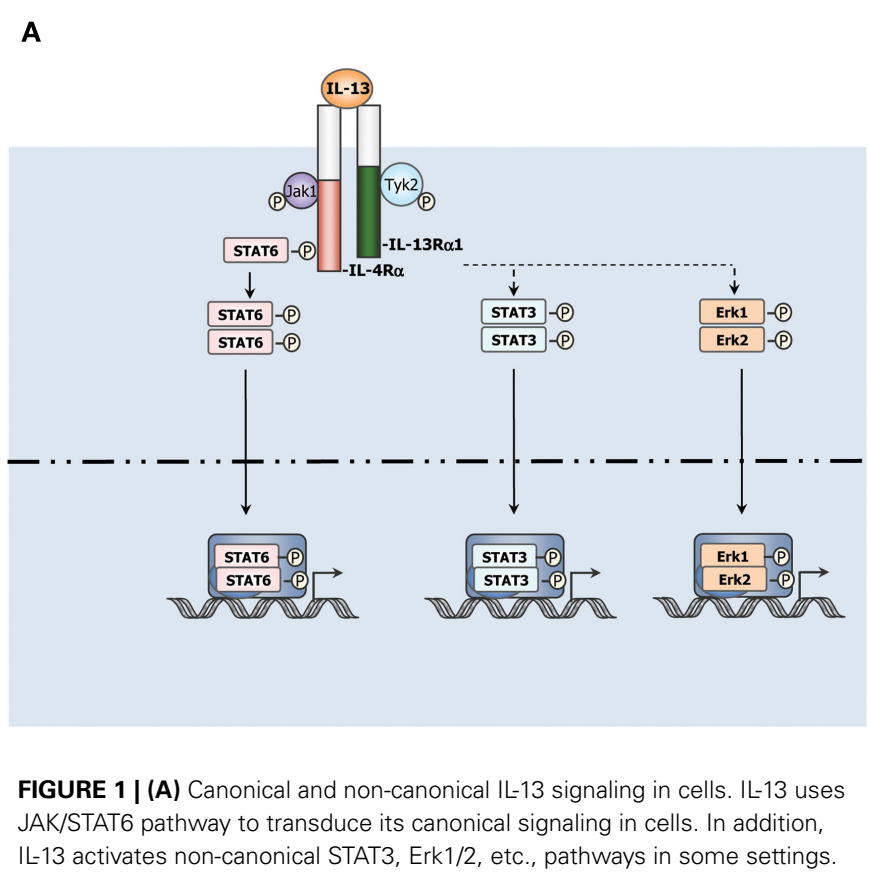

B
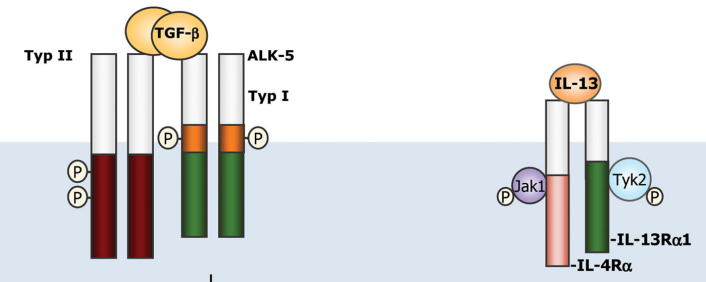

$\downarrow$ $\downarrow$

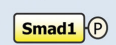

Smad1 $P$

Smad2 $P$

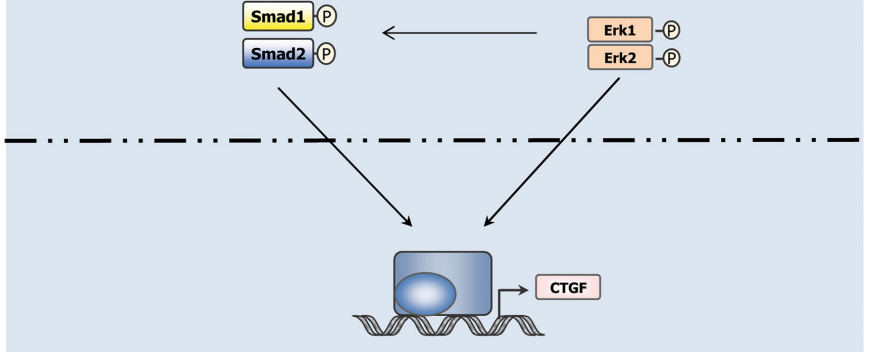

IL-13 activates non-canonical STAT3, Erk1/2, etc., pathways in some settings.

(B) Non-canonical signaling pathways of IL-13 play a critical role in liver fibrosis. IL-13 interacts with TGF- $\beta$ signaling pathway to induce CTGF expression in HSCs via Erk1/2 pathway (Liu et al., 2011). 
nevertheless provide us new insights for understanding IL-13 function and signaling in different fibrotic diseases. More advanced acknowledge with IL-13R $\alpha 2$ is thus eagerly awaited.

Given that both TGF- $\beta 1$ and IL- 13 are critical for organ fibrosis, synergic signaling crosstalk during fibrogenesis between these two major pro-fibrotic cytokines is always a hot topic. IL-13 cooperates with TGF- $\beta 1$ to induce fibrosis in some settings (Lee et al., 2001; Lanone et al., 2002; Fichtner-Feigl et al., 2006). For example, IL-13 is known as a potent inducer of matrix metalloproteinases- 9 and cathepsin-based proteolytic pathways which stimulate cleavage of latency-associated peptide thus activate TGF- $\beta$ (Lee et al., 2001; Lanone et al., 2002). However, the mechanism of IL-13 induced fibrogenesis is far more complicated than expected. In the context of schistosoma infected mice, IL-13 induced liver fibrosis is independent of TGF- $\beta$ (Kaviratne et al., 2004). A more recent work studying CTGF induction in primary HSC further supported a TGF- $\beta$ independent mechanism involved in IL-13 induced liver fibrogenesis (Liu et al., 2011). IL-13 was found to induce CTGF in a TGF- $\beta$ independent manner in quiescent HSC, while this process still requires activation of Smad proteins and participation of TGF- $\beta$ type I receptors. Erk-MAPK signaling pathway was found at least partially to mediate the TGF- $\beta$ independent Smads activation involved in IL-13 stimulated CTGF production (Liu et al., 2011; Figure 1). These findings suggested that IL-13 mediated fibrosis may be not strictly dependent on the downstream TGF- $\beta$ actions. Besides through regulating the production and activation of TGF- $\beta$, IL-13 can also utilize other mechanisms to drive fibrogenesis.

Another controversial issue involved in IL-13 mediated fibrogenesis is the participation of Stat6. Signaling through IL-4R $\alpha /$ IL$13 \mathrm{R} \alpha 1$ supports Stat6 activation for both IL-4 and IL-13, which is consistent with the fact that IL-13 shares many functional properties with IL-4. Stat6 activation upon receptor engagement is suggested due to the recruitment of Stat 6 to the IL- $4 \mathrm{R} \alpha$ chain

\section{REFERENCES}

Akpolat, N., Yahsi, S., Godekmerdan, A., Demirbag, K., and Yalniz, M. (2005). Relationship between serum cytokine levels and histopathological changes of liver in patients with hepatitis B. World J. Gastroenterol. 11, 3260-3263.

Aliprantis, A. O., Wang, J., Fathman, J. W., Lemaire, R., Dorfman, D. M., Lafyatis, R., and Glimcher, L. H. (2007). Transcription factor T-bet regulates skin sclerosis through its function in innate immunity and via IL-13. Proc. Natl. Acad. Sci. U.S.A. 104, 2827-2830.

Alves Oliveira, L. F., Moreno, E. C., Gazzinelli, G., Martins-Filho, O. A., Silveira, A. M., Gazzinelli, A., Malaquias, L. C., LoVerde, P., Leite, P. M., and Correa-Oliveira, R. (2006). Cytokine production associated with periportal fibrosis during chronic Schistosomiasis mansoni in humans. Infect. Immun. 74, 1215-1221.
Bataller, R., and Brenner, D. A. (2005). Liver fibrosis. J. Clin. Invest. 115, 209-218.

Belperio, J. A., Dy, M., Burdick, M. D., Xue, Y. Y., Li, K., Elias, J. A., and Keane, M. P. (2002). Interaction of IL-13 and C10 in the pathogenesis of bleomycin-induced pulmonary fibrosis. Am. J. Respir. Cell Mol. Biol. 27, 419-427.

Bergamini, A., Bolacchi, F., Cerasari, G., Carvelli, C., Faggioli, E., Cepparulo, M., Demin, F., Uccella, I., Bongiovanni, B., Niutta, P., Capozzi, M., Lupi, M., Piscitelli, E., Rocchi, G., and Angelico, M. (2001). Lack of evidence for the Th2 predominance in patients with chronic hepatitis C. Clin. Exp. Immunol. 123, 451-458.

Blease, K., Jakubzick, C., Westwick, J., Lukacs, N., Kunkel, S. L., and Hogaboam, C. M. (2001). Therapeutic effect of IL-13 immunoneutralization during chronic experimental fungal asthma. J. Immunol. 166, 5219-5224.

(Kelly-Welch et al., 2003). A number of studies have demonstrated that the IL-13, IL-4R $\alpha$, and Stat6 pathway is critical for development of fibrosis (Fallon et al., 2001; Lee et al., 2001; Chiaramonte et al., 2003). On the other hand, several studies argued that IL-13regulated response, including lung and liver fibrosis, could develop in the absence of Stat6 (Blease et al., 2002; Fritz et al., 2011; Liu et al., 2011). A study based on liver tissue from patients with different chronic liver diseases revealed that only 5 of 120 IL-13 positive liver tissue specimens exhibited positive p-Stat6 staining (Weng et al., 2009), indicating that a Stat6 independent mechanism is implicated in IL-13 associated liver fibrosis.

\section{PERSPECTIVE}

It has been confirmed that IL-13 is a critical pro-fibrotic factor in liver fibrosis associated with Schistosoma infection. In cultured HSC, IL-13 directly up-regulates expression of collagens and other pro-fibrotic genes. Recently, the potential role of IL-13 in non-Schistosoma induced liver fibrogenesis has been uncovered. The IL-13 receptors, IL-13R $\alpha 1$ and IL-13R $\alpha 2$, play differently in IL-13 signaling pathway. IL-13R $\alpha 2$ serves as a decoy receptor in Schistosomiasis, but transmits signaling to activate TGF- $\beta 1$ promoter in NASH. What is the function of IL-13R $\alpha 2$ in other IL-13 related chronic liver diseases? Is it possible to use sIL-13R $\alpha 2-\mathrm{Fc}$ as a successful drug to treat liver fibrosis in Schistosomiasis patients? What kind of role is Stat6 playing in different diseases settings? These are some eager questions waiting to be explored in the near future.

\section{ACKNOWLEDGMENTS}

The study was supported by the Returned Overseas Chinese Scholars, State Education Ministry (Starting Research Foundation for the Returned Overseas Chinese Scholars, J20050337491010G50523), People's Republic of China (Hong-Lei Weng), ElseKröner Fresenius (Hong-Lei Weng).

Blease, K., Schuh, J. M., Jakubzick, C., Lukacs, N. W., Kunkel, S. L., Joshi, B. H., Puri, R. K., Kaplan, M. H., and Hogaboam, C. M. (2002). Stat6-deficient mice develop airway hyperresponsiveness and peribronchial fibrosis during chronic fungal asthma. Am. J. Pathol. 160, 481-490.

Booth, M., Mwatha, J. K., Joseph, S., Jones, F. M., Kadzo, H., Ireri, E., Kazibwe, F., Kemijumbi, J., Kariuki, C. Kimani, G., Ouma, J. H., Kabatereine, N. B., Vennervald, B. J., and Dunne, D. W. (2004). Periportal fibrosis in human Schistosoma mansoni infection is associated with low IL-10, low IFN-gamma, high TNFalpha, or low RANTES, depending on age and gender. J. Immunol. 172, 1295-1303.

Cheever, A. W., Poindexter, R. W., and Wynn, T. A. (1999). Egg laying is delayed but worm fecundity is normal in SCID mice infected with Schistosoma japonicum and S. mansoni with or without recombinant tumor necrosis factor alpha treatment. Infect. Immun. 67, 2201-2208.

Cheever, A. W., Williams, M. E., Wynn, T. A., Finkelman, F. D., Seder, R. A., Cox, T. M., Hieny, S., Caspar, P., and Sher, A. (1994). Anti-IL-4 treatment of Schistosoma mansoni-infected mice inhibits development of $\mathrm{T}$ cells and non-B, non- $\mathrm{T}$ cells expressing Th2 cytokines while decreasing egginduced hepatic fibrosis. J. Immunol. 153, 753-759.

Chiaramonte, M. G., Cheever, A. W., Malley, J. D., Donaldson, D. D., and Wynn, T. A. (2001). Studies of murine schistosomiasis reveal interleukin-13 blockade as a treatment for established and progressive liver fibrosis. Hepatology 34, 273-282.

Chiaramonte, M. G., Donaldson, D. D., Cheever, A. W., and Wynn, T. A. (1999a). An IL-13 inhibitor blocks the development of hepatic 
fibrosis during a T-helper type 2dominated inflammatory response. J. Clin. Invest. 104, 777-785.

Chiaramonte, M. G., Schopf, L. R., Neben, T. Y., Cheever, A. W., Donaldson, D. D., and Wynn, T. A. (1999b). IL-13 is a key regulatory cytokine for Th2 cell-mediated pulmonary granuloma formation and IgE responses induced by Schistosoma mansoni eggs. J. Immunol. 162, 920-930.

Chiaramonte, M. G., Mentink-Kane, M., Jacobson, B. A., Cheever, A. W., Whitters, M. J., Goad, M. E., Wong, A., Collins, M., Donaldson, D. D., Grusby, M. J., and Wynn, T. A. (2003). Regulation and function of the interleukin 13 receptor alpha 2 during a $\mathrm{T}$ helper cell type 2dominant immune response. J. Exp. Med. 197, 687-701.

Coutinho, H. M., Acosta, L. P., Wu, H. W., McGarvey, S. T., Su, L., Langdon, G. C., Jiz, M. A., Jarilla, B., Olveda, R. M., Friedman, J. F., and Kurtis, J. D. (2007). Th2 cytokines are associated with persistent hepatic fibrosis in human Schistosoma japonicum infection. J. Infect. Dis. 195, 288-295.

de Jesus, A. R., Magalhaes, A., Miranda, D. G., Miranda, R. G., Araujo, M. I., de Jesus, A. A., Silva, A., Santana, L. B., Pearce, E., and Carvalho, E. M. (2004). Association of type 2 cytokines with hepatic fibrosis in human Schistosoma mansoni infection. Infect. Immun. 72, 3391-3397.

de Lalla, C., Galli, G., Aldrighetti, L., Romeo, R., Mariani, M., Monno, A., Nuti, S., Colombo, M., Callea, F., Porcelli, S. A., Panina-Bordignon, P., Abrignani, S., Casorati, G., and Dellabona, P. (2004). Production of profibrotic cytokines by invariant NKT cells characterizes cirrhosis progression in chronic viral hepatitis. J. Immunol. 173, 1417-1425.

Donaldson, D. D., Whitters, M. J., Fitz, L. J., Neben, T. Y., Finnerty, H., Henderson, S. L., O'Hara, R. M. Jr., Beier, D. R., Turner, K. J., Wood, C. R., and Collins, M. (1998). The murine IL-13 receptor alpha 2: molecular cloning, characterization, and comparison with murine IL-13 receptor alpha 1. J. Immunol. 161, 2317-2324.

Durante-Mangoni, E., Wang, R., Shaulov, A., He, Q., Nasser, I., Afdhal, N., Koziel, M. J., and Exley, M. A. (2004). Hepatic CD1d expression in hepatitis $\mathrm{C}$ virus infection and recognition by resident proinflammatory CD1d-reactive $\mathrm{T}$ cells. $J$. Immunol. 173, 2159-2166.

Fallon, P. G., Emson, C. L., Smith, P., and McKenzie, A. N. (2001). IL-13 overexpression predisposes to anaphylaxis following antigen sensitization. J. Immunol. 166, 2712-2716.

Fallon, P. G., Richardson, E. J., McKenzie, G. J., and McKenzie, A. N. (2000). Schistosome infection of transgenic mice defines distinct and contrasting pathogenic roles for IL4 and IL-13: IL-13 is a profibrotic agent. J. Immunol. 164, 2585-2591.

Fichtner-Feigl, S., Strober, W., Kawakami, K., Puri, R. K., and Kitani, A. (2006). IL-13 signaling through the IL-13alpha2 receptor is involved in induction of TGF-betal production and fibrosis. Nat. Med. 12, 99-106.

Friedman, S. L. (2008). Mechanisms of hepatic fibrogenesis. Gastroenterology 134, 1655-1669.

Fritz, D. K., Kerr, C., Fattouh, R., Llop-Guevara, A., Khan, W. I., Jordana, M., and Richards, C. D. (2011). A mouse model of airway disease: oncostatin M-induced pulmonary eosinophilia, goblet cell hyperplasia, and airway hyperresponsiveness are STAT6 dependent, and interstitial pulmonary fibrosis is STAT6 independent. J. Immunol. $186,1107-1118$

Gressner, A. M., Weiskirchen, R., Breitkopf, K., and Dooley, S. (2002). Roles of TGF-beta in hepatic fibrosis. Front. Biosci. 7, d793-d807.

Hasegawa, M., Fujimoto, M., Kikuchi, K., and Takehara, K. (1997). Elevated serum levels of interleukin 4 (IL4), IL-10, and IL-13 in patients with systemic sclerosis. J. Rheumatol. 24, 328-332.

Hauber, H. P., Gholami, D., Meyer, A., and Pforte, A. (2003). Increased interleukin-13 expression in patients with sarcoidosis. Thorax 58, 519-524.

Heller, F., Florian, P., Bojarski, C., Richter, J., Christ, M., Hillenbrand, B., Mankertz, J., Gitter, A. H., Burgel, N., Fromm, M., Zeitz, M., Fuss, I., Strober, W., and Schulzke, J. D. (2005). Interleukin-13 is the key effector Th2 cytokine in ulcerative colitis that affects epithelial tight junctions, apoptosis, and cell restitution. Gastroenterology 129, 550-564.

Hershey, G. K. (2003). IL-13 receptors and signaling pathways: an evolving web. J. Allergy Clin. Immunol. 111, 677-690; quiz 691.

Ingram, J. L., Rice, A. B., Geisenhoffer, K., Madtes, D. K., and Bonner, J. C. (2004). IL-13 and IL-1beta promote lung fibroblast growth through coordinated up-regulation of PDGF-AA and PDGF-Ralpha. FASEB J. 18, 1132-1134.
Inoue, M., Kanto, T., Miyatake, H., Itose, I., Miyazaki, M., Yakushijin, T. Sakakibara, M., Kuzushita, N., Hiramatsu, N., Takehara, T., Kasahara, A. and Hayashi, N. (2006). Enhanced ability of peripheral invariant natural killer T cells to produce IL-13 in chronic hepatitis $\mathrm{C}$ virus infection. $J$. Hepatol. 45, 190-196.

Iredale, J. P. (2007). Models of liver fibrosis: exploring the dynamic nature of inflammation and repair in a solid organ. J. Clin. Invest. 117, 539-548.

Isomaki, P., Luukkainen, R., Toivanen, P., and Punnonen, J. (1996) The presence of interleukin-13 in rheumatoid synovium and its antiinflammatory effects on synovia fluid macrophages from patients with rheumatoid arthritis. Arthritis Rheum. 39, 1693-1702.

Jakubzick, C., Choi, E. S., Carpenter, K. J., Kunkel, S. L., Evanoff, H., Martinez, F. J., Flaherty, K. R., Toews, G. B., Colby, T. V., Travis, W. D., Joshi, B. H., Puri, R. K., and Hogaboam, C. M. (2004). Human pulmonary fibroblasts exhibit altered interleukin-4 and interleukin-13 receptor subunit expression in idiopathic interstitial pneumonia. Am. J. Pathol. 164 1989-2001.

Jakubzick, C., Kunkel, S. L., Joshi, B. H., Puri, R. K., and Hogaboam, C. M. (2002). Interleukin-13 fusion cytotoxin arrests Schistosoma manson egg-induced pulmonary granuloma formation in mice. Am. J. Pathol. 161, 1283-1297.

Jankovic, D., Kullberg, M. C., NobenTrauth, N., Caspar, P., Ward, J. M., Cheever, A. W., Paul, W. E., and Sher, A. (1999). Schistosome-infected IL4 receptor knockout $(\mathrm{KO})$ mice, in contrast to IL-4 $\mathrm{KO}$ mice, fail to develop granulomatous pathology while maintaining the same lymphokine expression profile. J. Immunol. 163, 337-342.

Jin, Z., Sun, R., Wei, H., Gao, X., Chen, Y., and Tian, Z. (2011). Accelerated liver fibrosis in hepatitis B virus transgenic mice: involvement of natural killer T cells. Hepatology 53 219-229.

Joshi, B. H., Hogaboam, C., Dover, P., Husain, S. R., and Puri, R. K. (2006). Role of interleukin-13 in cancer, pulmonary fibrosis, and other $\mathrm{T}(\mathrm{H}) 2$ type diseases. Vitam. Horm. 74 479-504.

Kanto, T., and Hayashi, N. (2007). Innate immunity in hepatitis $\mathrm{C}$ virus infection: interplay among dendritic cells, natural killer cells and natural killer T cells. Hepatol. Res. 37(Suppl. 3), S319-S326.
Kaviratne, M., Hesse, M., Leusink, M., Cheever, A. W., Davies, S. J., McKerrow, J. H., Wakefield, L. M., Letterio, J. J., and Wynn, T. A. (2004). IL-13 activates a mechanism of tissue fibrosis that is completely TGFbeta independent. J. Immunol. 173, 4020-4029.

Kawashima, R., Kawamura, Y. I., Oshio, T., Son, A., Yamazaki, M., Hagiwara, T., Okada, T., Inagaki-Ohara, K., Wu, P., Szak, S., Kawamura, Y. J., Konishi, F., Miyake, O., Yano, H., Saito, Y., Burkly, L. C., and Dohi, T. (2011). Interleukin-13 damages intestinal mucosa via TWEAK and Fn14 in mice-a pathway associated with ulcerative colitis. Gastroenterology 141, 2119-2129; e2118.

Kelly-Welch, A. E., Hanson, E. M., Boothby, M. R., and Keegan A. D. (2003). Interleukin-4 and interleukin-13 signaling connections maps. Science 300, 1527-1528.

Kumar, R. K., Herbert, C., Yang, M., Koskinen, A. M., McKenzie, A. N., and Foster, P. S. (2002). Role of interleukin-13 in eosinophil accumulation and airway remodelling in a mouse model of chronic asthma. Clin. Exp. Allergy 32, 1104-1111.

Lanone, S., Zheng, T., Zhu, Z., Liu, W., Lee, C. G., Ma, B., Chen, Q., Homer, R. J., Wang, J., Rabach, L. A., Rabach, M. E., Shipley, J. M., Shapiro, S. D., Senior, R. M. and Elias, J. A. (2002). Overlapping and enzyme-specific contributions of matrix metalloproteinases- 9 and -12 in IL-13-induced inflammation and remodeling. J. Clin. Invest. 110 , 463-474.

Lee, C. G., Homer, R. J., Zhu, Z., Lanone, S., Wang, X., Koteliansky, V., Shipley, J. M., Gotwals, P., Noble, P., Chen, Q., Senior, R. M., and Elias, J. A. (2001). Interleukin-13 induces tissue fibrosis by selectively stimulating and activating transforming growth factor beta(1). J. Exp. Med. 194, 809-821.

Liu, Y., Meyer, C., Muller, A., Herweck, F., Li, Q., Mullenbach, R., Mertens, P. R., Dooley, S., and Weng, H. L. (2011). IL-13 induces connective tissue growth factor in rat hepatic stellate cells via TGF-beta-independent Smad signaling. J. Immunol. 187, 2814-2823.

Mann, D. A., and Marra, F. (2010). Fibrogenic signalling in hepatic stellate cells. J. Hepatol. 52, 949-950.

Matsushita, M., Yamamoto, T., and Nishioka, K. (2004). Upregulation of interleukin-13 and its receptor in a murine model of bleomycininduced scleroderma. Int. Arch. Allergy Immunol. 135, 348-356. 
Mentink-Kane, M. M., Cheever, A. W., Thompson, R. W., Hari, D. M., Kabatereine, N. B., Vennervald, B. J., Ouma, J. H., Mwatha, J. K., Jones, F. M., Donaldson, D. D., Grusby, M. J., Dunne, D. W., and Wynn, T. A. (2004). IL-13 receptor alpha 2 downmodulates granulomatous inflammation and prolongs host survival in schistosomiasis. Proc. Natl. Acad. Sci. U.S.A. 101, 586-590.

Metwali, A., Elliott, D., Blum, A. M., Li, J., Sandor, M., Lynch, R., Noben-Trauth, N., and Weinstock, J. V. (1996). The granulomatous response in murine Schistosomiasis mansoni does not switch to Th1 in IL-4-deficient C57BL/6 mice. J. Immunol. 157, 4546-4553.

Park, S. W., Ahn, M. H., Jang, H. K., Jang, A. S., Kim, D. J., Koh, E. S., Park, J. S., Uh, S. T., Kim, Y. H., Paik, S. H., Shin, H. K., Youm, W., and Park, C. S. (2009). Interleukin-13 and its receptors in idiopathic interstitial pneumonia: clinical implications for lung function. J. Korean Med. Sci. 24, 614-620.

Pearce, E. J., Cheever, A., Leonard, S., Covalesky, M., Fernandez-Botran, R., Kohler, G., and Kopf, M. (1996). Schistosoma mansoni in IL4-deficient mice. Int. Immunol. 8, 435-444.

Riccieri, V., Rinaldi, T., Spadaro, A., Scrivo, R., Ceccarelli, F., Franco, M. D., Taccari, E., and Valesini, G. (2003). Interleukin-13 in systemic sclerosis: relationship to nailfold capillaroscopy abnormalities. Clin. Rheumatol. 22, 102-106.

Roulot, D., Durand, H., Coste, T., Rautureau, J., Strosberg, A. D., Benarous, R., and Marullo, S. (1995). Quantitative analysis of transforming growth factor betal messenger RNA in the liver of patients with chronic hepatitis C: absence of correlation between high levels and severity of disease. Hepatology 21, 298-305.

Saiki, O., Uda, H., Nishimoto, N., Miwa, T., Mima, T., Ogawara, T., Azuma, N., Katada, Y., Sawaki, J., Tsutsui, H., Matsui, K., Maeda, A., and Nakanishi, K. (2004). Adult Still's disease reflects a Th2 rather than a Th1 cytokine profile. Clin. Immunol. 112, 120-125.

Shimamura, T., Fujisawa, T., Husain, S. R., Kioi, M., Nakajima, A., and Puri, R. K. (2008). Novel role of IL-13 in fibrosis induced by nonalcoholic steatohepatitis and its amelioration by IL-13R-directed cytotoxin in a rat model. J. Immunol. 181, 4656-4665.

Spadaro, A., Rinaldi, T., Riccieri, V., Taccari, E., and Valesini, G. (2002). Interleukin-13 in autoimmune rheumatic diseases: relationship with the autoantibody profile. Clin. Exp. Rheumatol. 20, 213-216.

Stickel, F., Urbaschek, R., Schuppan, D., Poeschl, G., Oesterling, C., Conradt, C., McCuskey, R. S., Simanowski, U. A., and Seitz, H. K. (2001). Serum collagen type VI and XIV and hyaluronic acid as early indicators for altered connective tissue turnover in alcoholic liver disease. Dig. Dis. Sci. 46, 2025-2032.

Sugimoto, R., Enjoji, M., Nakamuta, M., Ohta, S., Kohjima, M., Fukushima, M., Kuniyoshi, M., Arimura, E., Morizono, S., Kotoh, K., and Nawata, H. (2005). Effect of IL-4 and IL-13 on collagen production in cultured LI90 human hepatic stellate cells. Liver Int. 25, 420-428.

Toh, M. L., and Miossec, P. (2007). The role of $\mathrm{T}$ cells in rheumatoid arthritis: new subsets and new targets. Curr. Opin. Rheumatol. 19, 284-288.

Tokayer, A., Carsons, S. E., Chokshi, B., and Santiago-Schwarz, F. (2002). High levels of interleukin
13 in rheumatoid arthritis sera are modulated by tumor necrosis factor antagonist therapy: association with dendritic cell growth activity. $J$. Rheumatol. 29, 454-461.

Weng, H. L., Liu, Y., Chen, J. L., Huang, T., Xu, L. J., Godoy, P., Hu, J. H., Zhou, C., Stickel, F., Marx, A., Bohle, R. M., Zimmer, V., Lammert, F., Mueller, S., Gigou, M., Samuel, D., Mertens, P. R., Singer, M. V., Seitz, H. K., and Dooley, S. (2009). The etiology of liver damage imparts cytokines transforming growth factor betal or interleukin-13 as driving forces in fibrogenesis. Hepatology 50, 230-243.

Wilson, M. S., Ramalingam, T. R., Rivollier, A., Shenderov, K., MentinkKane, M. M., Madala, S. K., Cheever, A. W., Artis, D., Kelsall, B. L., and Wynn, T. A. (2011). Colitis and intestinal inflammation in IL10-/mice results from IL-13Ralpha2mediated attenuation of IL-13 activity. Gastroenterology 140, 254-264.

Wynn, T. A. (2003). IL-13 effector functions. Annu. Rev. Immunol. 21, 425-456.

Wynn, T. A. (2004). Fibrotic disease and the $\mathrm{T}(\mathrm{H}) 1 / \mathrm{T}(\mathrm{H}) 2$ paradigm. Nat. Rev. Immunol. 4, 583-594.

Wynn, T. A. (2008). Cellular and molecular mechanisms of fibrosis. $J$. Pathol. 214, 199-210.

Wynn, T. A., Hesse, M., Sandler, N. G., Kaviratne, M., Hoffmann, K. F., Chiaramonte, M. G., Reiman, R., Cheever, A. W., Sypek, J. P., and Mentink-Kane, M. M. (2004a). Pselectin suppresses hepatic inflammation and fibrosis in mice by regulating interferon gamma and the IL-13 decoy receptor. Hepatology 39, 676-687.

Wynn, T. A., Thompson, R. W., Cheever, A. W., and Mentink-Kane, M. M. (2004b). Immunopathogenesis of schistosomiasis. Immunol. Rev. 201, 156-167.

Zhang, J. G., Hilton, D. J., Willson, T. A., McFarlane, C., Roberts, B. A., Moritz, R. L., Simpson, R. J., Alexander, W. S., Metcalf, D., and Nicola, N. A. (1997). Identification, purification, and characterization of a soluble interleukin (IL)-13-binding protein. Evidence that it is distinct from the cloned Il-13 receptor and Il-4 receptor alpha-chains. J. Biol. Chem. 272, 9474-9480.

Zhu, Z., Homer, R. J., Wang, Z., Chen, Q., Geba, G. P., Wang, J., Zhang, Y., and Elias, J. A. (1999). Pulmonary expression of interleukin-13 causes inflammation, mucus hypersecretion, subepithelial fibrosis, physiologic abnormalities, and eotaxin production. J. Clin. Invest. 103, 779-788.

Conflict of Interest Statement: The authors declare that the research was conducted in the absence of any commercial or financial relationships that could be construed as a potential conflict of interest.

Received: 15 January 2012; accepted: 23 April 2012; published online: 11 May 2012.

Citation: Liu Y, Munker S, Müllenbach R and Weng $H$-L (2012) IL-13 signaling in liver fibrogenesis. Front. Immun. 3:116. doi: 10.3389/fimmu.2012.00116

This article was submitted to Frontiers in $T$ Cell Biology, a specialty of Frontiers in Immunology.

Copyright () 2012 Liu, Munker, Müllenbach and Weng. This is an open-access article distributed under the terms of the Creative Commons Attribution Non Commercial License, which permits noncommercial use, distribution, and reproduction in other forums, provided the original authors and source are credited. 